\title{
Supratentorial Extraventricular Anaplastic Ependymoma Presented With Headache in Pregnancy: Case Report and Review of the Literature
}

\author{
Vaner Koksal $^{\mathrm{a}, \mathrm{d}}$, Selim Kayaci ${ }^{\mathrm{a}}$, Recep Bedir ${ }^{\mathrm{b}}$, Gulsah Balik ${ }^{\mathrm{c}}$
}

\begin{abstract}
Supratentorial extraventricular anaplastic ependymoma (SEAE) is a rare type of ependymoma. On magnetic resonance imaging (MRI), generally it is noted with a solid appearance or a mixed solid and cystic pattern. A 28 -year-old female was admitted to our clinic with a complaint of increasing headaches in the third trimester of pregnancy and epileptic seizures in the first week postpartum. A superficial cortical lesion was found in the left precentral gyrus anterior, showing as purely cystic on the MRI. Gross total microsurgical resection was performed. Histological and immunohistochemical examinations confirmed the finding of anaplastic ependymoma. In this article, the course of SEAE is described that starting with pregnancy. And SEAE in this patient was investigated regarding different features from other similar cases. Also, the effect of pregnancy on this tumor's growth, which is known to have an embryonal origin, is discussed.
\end{abstract}

Keywords: Anaplastic ependymoma; Cystic tumor; Extraventricular tumor; Pregnancy; Supratentorial tumor

\section{Introduction}

Ependymoma is a glial neoplasm arising from ependymal cells inside the fourth ventricle and encircles the central canal in the spinal cord [1-5]. Ependymoma accounts for $2-9 \%$ of all glial neuroepithelial tumors $[6,7]$. The incidence rate of ependymoma is higher in children. But it is much less seen in adults [6]. Anaplastic ependymoma is the most aggressive

Manuscript accepted for publication September 17, 2015

aDepartment of Neurosurgery, Medical School, Recep Tayip Erdogan University, Rize, Turkey

bDepartment of Pathology, Medical School, Recep Tayip Erdogan University, Rize, Turkey

'Department of Obstetrics and Gynecology, Medical School, Recep Tayip Erdogan University, Rize, Turkey

${ }^{\mathrm{d} C o r r e s p o n d i n g ~ A u t h o r: ~ V a n e r ~ K o k s a l, ~ D e p a r t m e n t ~ o f ~ N e u r o s u r g e r y, ~ M e d i c a l ~}$ School, Recep Tayip Erdogan University, Rize City, Turkey.

Email: vanerkoksal@hotmail.com

doi: http://dx.doi.org/10.14740/jmc2306w form [6]. Anaplastic ependymoma accounts for 8.6-11.5\% of all ependymoma [8]. According to the World Health Organization's (WHO) 2007 classification of central nervous system tumors, low-grade ependymoma was grade 2 and anaplastic ependymoma was grade $3[9,10]$. Ependymomas located outside the ventricles are called ectopic, cortical, lobar or extraventricular ependymomas $[11,12]$.

Supratentorial extraventricular anaplastic ependymoma (SEAE) arises outside of the ventricles, having any connections to the ventricles. SEAE is a very rare pathology [8]. There are only 47 cases of SEAE in the literature $[12,13]$. We found 20 reported cases or case series that had the same characteristics as this study prior to June 2014 (Table 1) [6, 8, $9,12,14-29]$. Only one reported case dealt with pregnancy [4, $12,13]$. We report a case of a patient with an SEAE that presented with a pregnant and purely cystic appearance on MRI and computed tomography (CT).

\section{Case Report}

A 28-year-old female had no complaints during the first 6 months of her pregnancy, but in the last 3 months, she suffered increasing headaches and involuntary spasms in her right arm. In the 2 weeks before the birth, severe headaches and loss of control complaints started. In the first week postpartum, the monoparesis in the right arm increased more and a speech disorder, due to dysarthria and focal seizure, presented. With these complaints, patient was admitted to the neurosurgery clinic; on cranial CT images in the second week postpartum, a pure cystic mass about $3 \times 4 \mathrm{~cm}$ in size was shown inside the left superficial precentral gyrus (Fig. 1a). The tumor appeared as a hypointense cystic mass on the T1-weighted MRI and hyperintense on the T2-weighted MRI images (Fig. 1c). However, there was not a solid part of, nor were there connections to, ventricles (Fig. 1c). There was minimal surrounding peritumoral brain edema (Fig. 1c, d). After an injection of gadolinium, enhancement was peripherally ring shaped (Fig. 1d).

In surgery, a left temporoparietal craniotomy was performed. After opening the dura flap, we stayed in front of the precentral gyrus and reached $2-3 \mathrm{~mm}$ distance from the cortical sulci to the mass. We encountered the mass without a capsule and the solid part. There was minimal necrosis and the cyst fluid was clear. The ventricle was not opened. The ini- 
Table 1. Summary of 47 Cases With Supratentorial Cortical Anaplastic Ependymoma (WHO Grade 3) Before June 2014 in the Literature (No Connection to the Ventricles) [6, 8, 9, 12, 14-29]

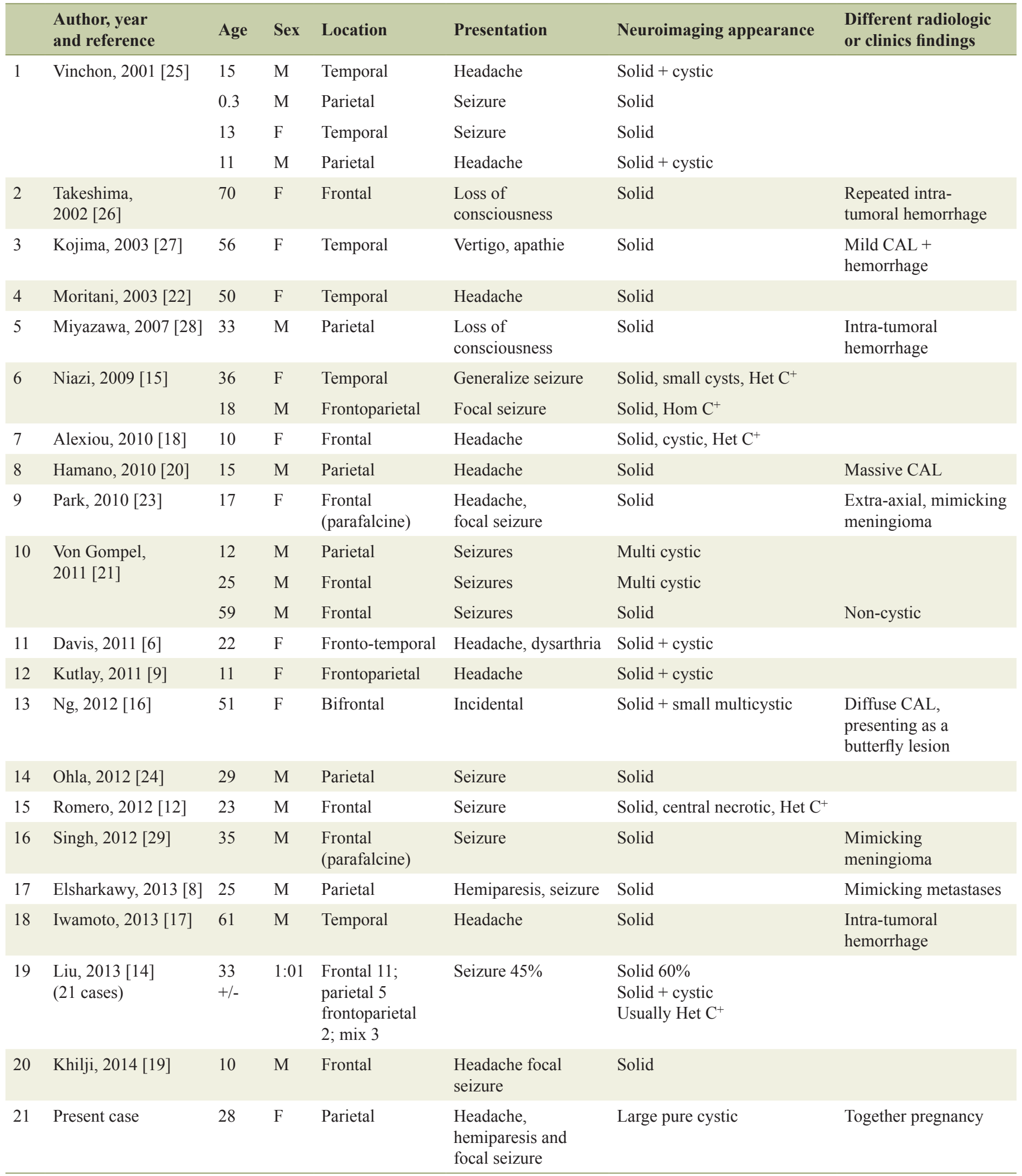

M: male; F: female; C+: contrast enhancement; CAL: calcification; Het: heterogeneous; Hom: homogeneous. 


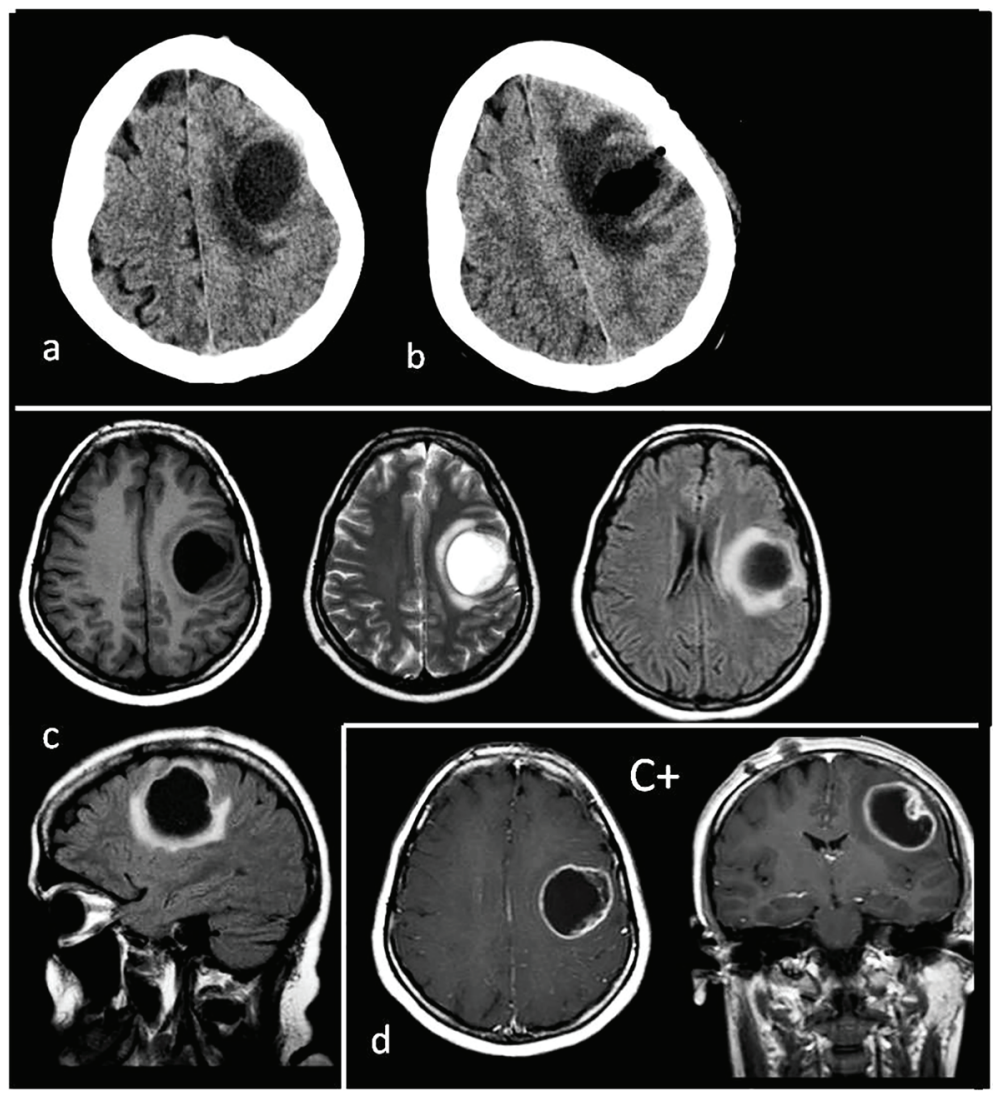

Figure 1. (a) Preoperative tomography to first diagnosis. (b) Postoperative tomography after the first operation. (c) Preoperative T1, T2, flair axial MR images and flair sagittal MR image to first diagnosis. (d) T1 axial and coronal MRI with gadolinium enhancement $\left(\mathrm{C}^{+}\right)$to first diagnosis. Tumor appearance cystic, intra-cortical and near cortical surface.

tial surgical view was suggestive of metastases or tumefactive multiple sclerosis (MS). The cyst wall was scraped. Eventually, gross total resection was achieved.

In a histopathological examination by hematoxylin and eosin staining, a high mitotic index and perivascular pseudorosettes were detected. The percentage of anaplasty inside the tumor was above $75 \%$. The tumor was also diffusedly stained with GFAP, S-100, and CD99 (Table 2) [7, 17]. It was diagnosed as a WHO grade 3 anaplastic ependymoma (Fig. 2a-d).

In the postoperative term, dysphasia and monoparesis in the right arm decreased. However, 2 months after the operation, it was seen that the mass had grown larger (Fig. 3a-c) and a second resection was carried out (Fig. 3d). The cranium was not closed after the operation. Four months after the second operation, the patient's headaches gradually increased. When the epileptic seizures could not be controlled with medication, a third resection was carried out (Fig. 4a). In the final operation, the cranium defect was enlarged and the skin was closed after a large duraplasty on the brain (Fig. 4b). It was observed that the cystic mass reformed in the next 3-month period (Fig. 4c). Within this period, the patient's general condition was good, except for the hemiparesis on the right side and behavioral changes. The mass content was aspirated twice with punctures. The patient chose not to accept radiotherapy. At the end of 9-month medical and surgical treatment, cerebral herniation developed and the patient's death occurred (Fig. 4d). Patient

Table 2. Immunohistochemical Findings of Brain Cortical Tumors [7, 17]

\begin{tabular}{llllll} 
Tumor type & GFAP & S-100 protein & Vimentin & CD99 & Pan-CK \\
\hline Anaplastic ependymoma & + & + & - & + & - \\
Anaplastic meningioma & - & $+(\mathrm{R})$ & + & - & - \\
Glioblastoma multiforme & + & + & - & - & - \\
Oligodendroglioma & $+(\mathrm{R})$ & + & - & - & - \\
Metastase of epithelial tumor & - & - & - & - & + \\
\hline
\end{tabular}

The differential diagnosis was made according to the table with immunohistochemical findings. GFAP: glial fibrillary acidic protein; Pan-CK: pan-cytokeratin; R: rare. 

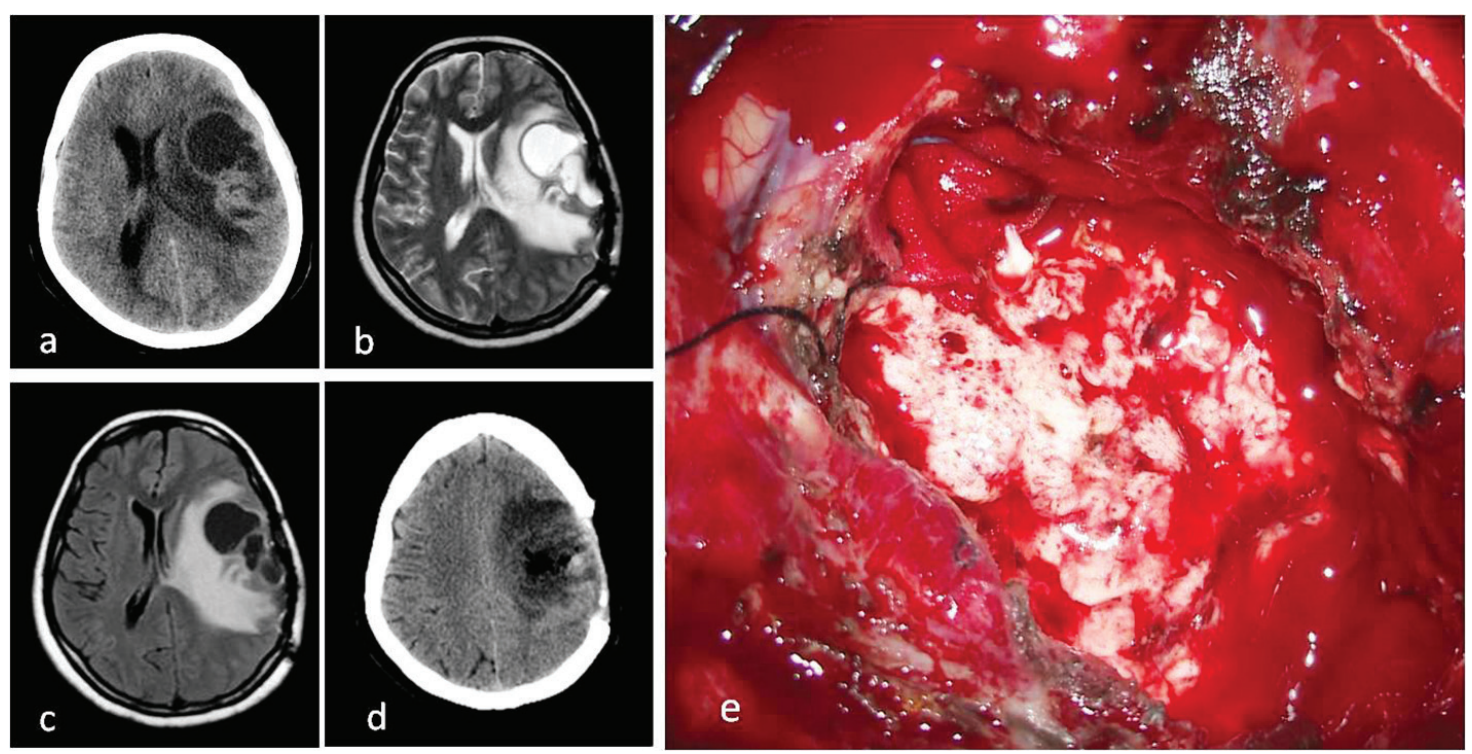

Figure 2. (a) Cystic mass on CT image before second operation. (b) T2 axial MRI. (c) FLAIR axial MRI. (d) CT image after second operation. (e) Intraoperative macroscopic appearance of tumor with surgery microscope.
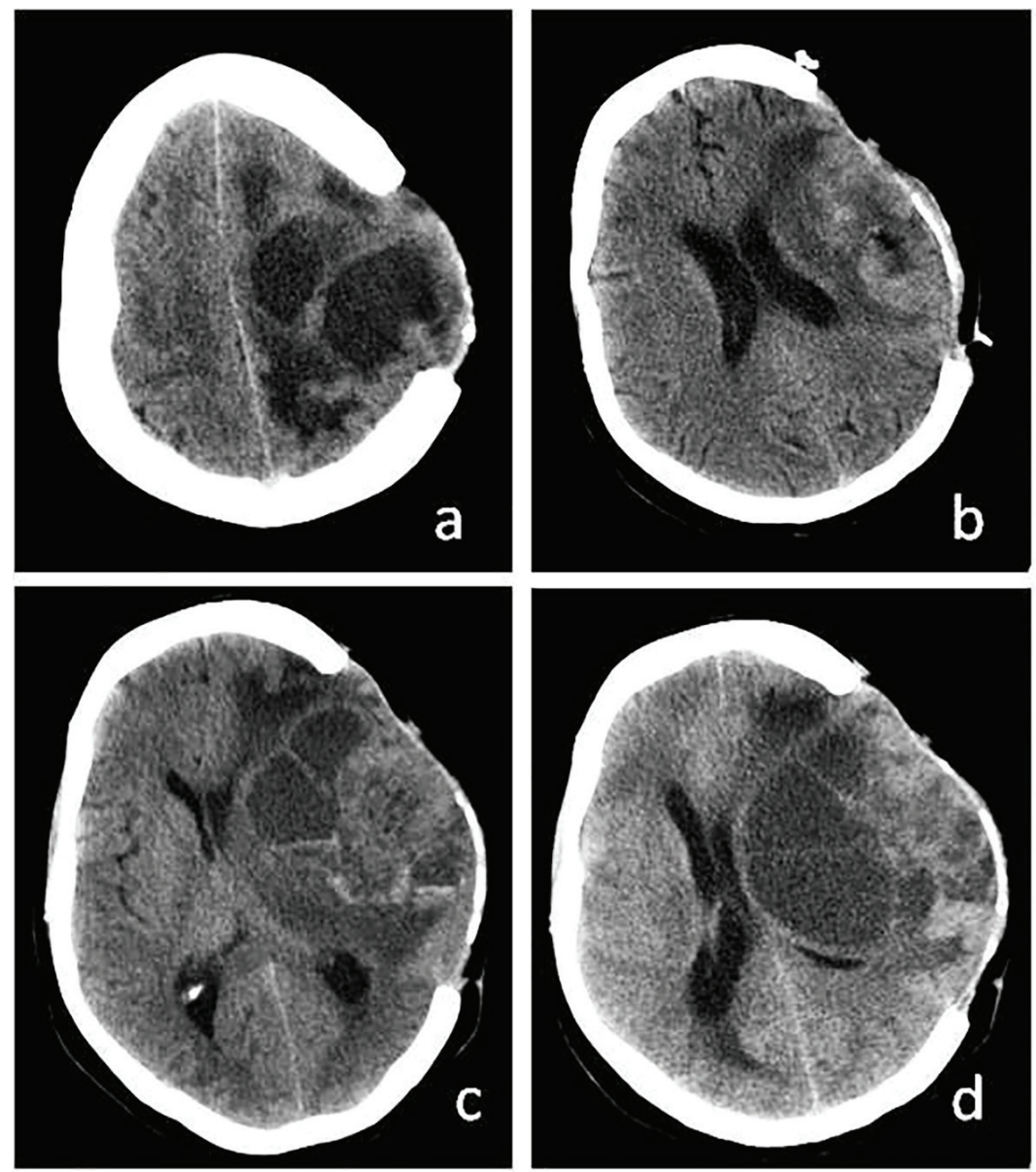

Figure 3. (a) Recurrence of cystic mass on CT before third operation. (b) More calvarial decompression and tumor resection after third operation. (c) Again recurrence of cystic mass. (d) Recurrence of cystic mass before exitus. 


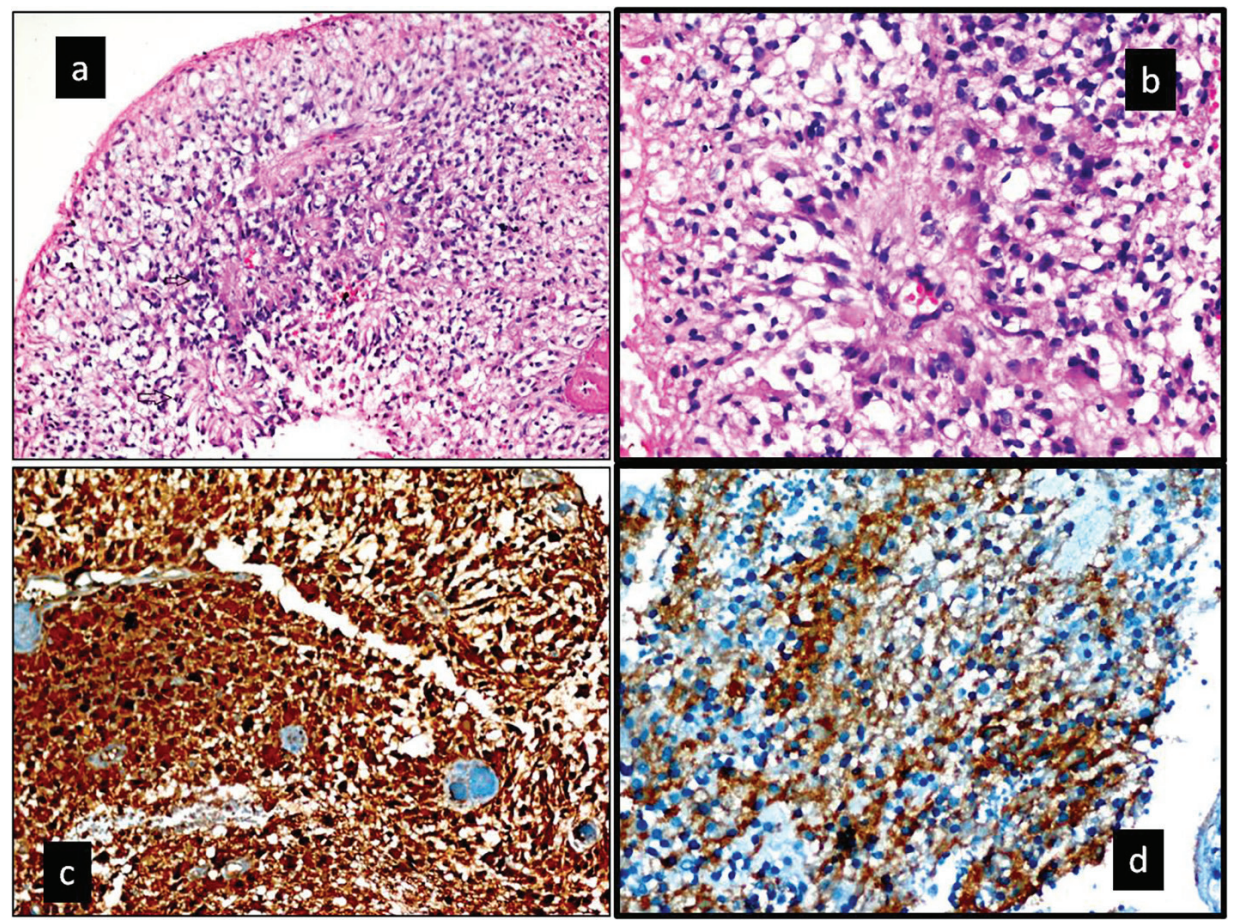

Figure 4. (a, b) Hematoxylin and eosin-stained section. (a) Increased cellularity with perivascualr pseudorosettes and a high mitotic index (black arrow) (× 200). (b) Pseudorosettes lined by pleomorphic cells with nuclear atypia and mitotic figures. Typical features for anaplastic ependymoma (H\&E, $\times 400)$. (c, d) Immunohistochemical staining. (c) Tumor was diffuse positive with S-100 protein $(\times 200)$. (d) Tumor was diffuse positive with CD99 protein $(\times 400)$. Ki-67 labeling index in the anaplastic component was $75 \%$ in the tumor. In addition, tumor was diffuse positive with GFAP.

with pregnancy depression could not be given any medical chemotherapeutic drugs. In spite of everything, the aggressive growth of the tumor could not be prevented.

\section{Discussion}

Intracranial ependymoma is commonly located in the posterior fossa and children, accounting for $10 \%$ of pediatric brain tumors [14]. However, they are relatively rare in adults. Supratentorial ependymomas are usually not related to the ventricular system. They are frequently located adjacent to the cortical surface, similar to our case $[4,10,15]$. Supratentorial ependymomas in adults are unusual lesions, often found to be of the anaplastic variant [16]. While the tumors that form in the lateral ventricle expand toward the cerebral tissue, tumors may also sometimes appear purely in a cortical location $[4,12$, 17]. The described tumor (SEAE) is extraordinarily rare. And SEAE is likely located in the frontal and parietal superficial cortexes [14].

There is a hypothesis that extraventricular or cortical ependymomas may form from the insertion of an embryonic ependymal tissue remnant into the cerebral cortex during the brain parenchyma's development $[7,30]$. Within this, it has been reported that, although they generally form in the nervous system, they also very rarely form extracranially [11]. It is thought that extracranial ependymomas grow when the patient is carrying an embryo from remnants in the neural tube or mul- tiply from teratomas $[18,31]$. It has been reported that, from the remnants left in the neural tube, ependymomas may develop in the sacrococcygeal extraspinal region, ovaries, paraovarian tissues, the omentum, the posterior mediastinum, and even in the lungs $[18,31]$. In the literature, there are very few ovarian ependymoma cases reported [11].

Supratentorial ependymomas generally originate from the third or, less likely, lateral ventricle walls and grow from there $[18,19,32,33]$. During their growth, they might reach the cerebral cortex surface and even hold onto the pial surface $[8$, 14]. When the SEAE has a cortical location, they may not be detected until they reach a very large size [30]. SEAE just like other cortical tumor lesions, generally causes seizures. There might also be complaints, such as focal neurological deficit, vomiting, and headache, all related to intracranial pressure [30]. As in our case, it has been reported that the clinical features appear as they expand toward the cortex's surface [32].

As they do not have typical images radiologically, it is not possible to distinguish supratentorial glial tumors [32]. While normal white matter is iso- or hypointense around the lesion on non-contrast T1 MRI, it might appear as hyperintense on T2 images. Signal heterogeneity exists in focal lesions, and necrosis focals are often found on these tumors. They are contrasted at variable rates, but, generally, they have a necrotic surface, both on CT and MRI, with medium contrasting on the centers $[1,6]$. Generally, they might have both solid and cystic components of larger than $4 \mathrm{~cm} \mathrm{[30].} \mathrm{Due} \mathrm{to} \mathrm{their} \mathrm{location} \mathrm{and}$ radiological features, low-grade astrocytoma must have a his- 
Table 3. Comparison of Pregnant Case With Anaplastic Ependymomas [44]

\begin{tabular}{|c|c|c|c|c|c|c|c|c|}
\hline 1 & $\begin{array}{l}\text { Kaminski, } \\
2003[44]\end{array}$ & 18 & $\mathrm{~F}$ & Posterior fossa in 4 ventricle & Started first trimester & Headache, apathy & Solid & $\begin{array}{l}\text { Operated in } \\
\text { first trimester }\end{array}$ \\
\hline 2 & $\begin{array}{l}\text { Present } \\
\text { case (2014) }\end{array}$ & 28 & $\mathrm{~F}$ & Parietal cortex & Started third trimester & Headache, hemiparesis & Purely cystic & Operated after birth \\
\hline
\end{tabular}

topathological differential diagnosis from glioblastoma multiforme, primitive neuroectodermal tumors, ganglioglioma, and oligodendroglioma $[3,20]$. Furthermore, in the first detection of the case, it was thought that its superficial, purely cystic appearance and minimal peritumoral edema might belong to tumefactive multiple sclerosis [34]. We waited to see whether the patient would respond to the methasone. When no change was seen in the lesion-control MRI, a surgical resection decision was made. The necessary histopathological differential diagnosis is shown in Table 2.

In the histological aspect, tumor cells characteristically contain perivascular pseudo-rosettes, and, to a lesser extent, ependymal rosettes $[3,7]$. In a pathological examination, according to the WHO classification, ependymomas are divided into four groups. They are classified as subependymoma, myxopapillary ependymoma, classic ependymoma, and anaplastic ependymoma. Anaplastic ependymoma, as found in our case, has characteristics of high cellularity, variable nuclear atypia, significant mitotic activity, significant vascular proliferation, and cellular structure defects, and is reported as a WHO grade 3 malignant character tumor [7, 17, 35]. As the high-grade intracranial malignant tumoral lesions have an abnormal and fragile vascular structure, they may cause spontaneous bleeding [17]. In our case, due to the increasing clotting tendency effect of pregnancy, intra-tumoral bleeding may not have formed. No intra-tumoral bleeding was shown in the MRI or computed tomography (CT) images of this case.

In our review of the literature, it was seen that SEAE emerged frequently as high-grade tumors in adults. Because of this, the prognosis is poor for SEAE. While median survival is 15 years in low-grade tumors, in high-grade tumors, the maximum survival is 1.5 years [30]. In the literature, the 5 -year survival rate without recurrence is $75 \%$, but, in those characterized as aggressive, this period is less than 31\% [21]. The severe negative prognostic criteria are determined as: a young age, incomplete tumor resection, histological anaplasia, and supratentorial localization $[12,17]$. It is reported that it is necessary to carry out an as-large-as-possible resection for SEAE characterized as anaplastic to reduce or eliminate recurrence [12]. But it relapsed after all resections. Due to their high mitotic activities, they are radiosensitive and postoperative radiotherapy is definitely recommended [22, 23, 35]. There are some who recommend radiotherapy, especially when incomplete resection was carried out, in only high-grade cases [24]. The patient had just completed her pregnancy and refused radiotherapy due to the worry that there may be adverse effects on the baby.

Co-occurrence of the pathology that presented with the pregnancy made us think that there was a relationship between them. There is multiplying from teratomas by means of pluripotent stem cells and their occurrence from embryonic origin remnants made us think that pregnancy had an effect on the formation of this tumor. Is it possible that the stem cell remnants inside the cerebral cortex, which have an ability to multiply and differentiate, were stimulated during the pregnancy? Possibly due to this, the clinical findings of this case appeared in the last trimester of the pregnancy. The role of hormone receptors in the growth of meningiomas that are meningotelial central nervous system tumors is known [36]. The presence of progesterone receptors was detected in $61 \%$ of meningiomas $[36,37]$. In this case, progesterone sensitivity like that of meningiomas was not detected using immunostaining.

Ependymoma patients have molecularly distinct diseases and that the heterogeneity seen on the chromosome level also applies at the gene expression level [38]. Different age-related immunohistochemical patterns and genetic variations have been found associated with the outcome of ependymoma patients; the main biological mechanisms are still unclear [39]. Therefore, direct effect of pregnancy was not found.

The relation between pregnancy and ependymoma was mentioned by Schweitzer et al in cauda equina ependymoma 15 case series [40]. Jaeger et al reported a lumbar ependymoma case that was first diagnosed in pregnancy [41]. The most frequent period in which lumbar ependymomas are seen is the third and fourth decades of life; this period is also compatible from a fertility angle. Is it possible that there is a factor in pregnancy facilitating the growth of ependymomas and their becoming symptomatic? The physiological changes occurring in the body that provide enough blood support to the placenta during the normal period of pregnancy consist of systemic vasodilation and rising cardiac output [42]. This condition results in an increase of perfusion in almost every organ in the body. Increased blood flow may lead to the provision of necessary blood support for the growth of an anaplastic tumor. The increase of headache in the last trimester of the pregnancy shows that the mass effect of the tumor had become evident in the final trimester. Only one similar case was found in the literature. However, the tumor had occurred during the first trimester and located infratentorially in the fourth ventricle (Table 3) [43, 44].

\section{Conclusion}

SEAE is rare in all studies and there are no absolute proofs about the etiology of SEAE [25-29, 45, 46]. However, from a neurological perspective, the evaluation of cases with severe headaches occurring during pregnancy can contribute to the early diagnosis of cranial pathologies of this kind. More comprehensive studies on pregnancy and neuroglial tumors to be carried out in the future will provide us with more benefits in determining the cause-and-effect relationship of these two 
conditions.

\section{References}

1. Centeno RS, Lee AA, Winter J, Barba D. Supratentorial ependymomas. Neuroimaging and clinicopathological correlation. J Neurosurg. 1986;64(2):209-215.

2. Kun LE, Kovnar EH, Sanford RA. Ependymomas in children. Pediatr Neurosci. 1988;14(2):57-63.

3. Molina OM, Colina JL, Luzardo GD, Mendez OE, Cardozo D, Velasquez HS, Cardozo JJ. Extraventricular cerebral anaplastic ependymomas. Surg Neurol. 1999;51(6):630-635.

4. Schwartz TH, Kim S, Glick RS, Bagiella E, Balmaceda C, Fetell MR, Stein BM, et al. Supratentorial ependymomas in adult patients. Neurosurgery. 1999;44(4):721-731.

5. Vaidya K, Smee R, Williams JR. Prognostic factors and treatment options for paediatric ependymomas. J Clin Neurosci. 2012;19(9):1228-1235.

6. Davis MJ, Hasan F, Weinreb I, Wallace MC, Kiehl TR. Extraventricular anaplastic ependymoma with metastasis to scalp and neck. J Neurooncol. 2011;104(2):599-604.

7. Ehtesham M, Kabos P, Yong WH, Schievink WI, Black KL, Yu JS. Development of an intracranial ependymoma at the site of a pre-existing cavernous malformation. Surg Neurol. 2003;60(1):80-82; discussion 83.

8. Elsharkawy AE, Abuamona R, Bergmann M, Salem S, Gafumbegete E, Rottger E. Cortical anaplastic ependymoma with significant desmoplasia: a case report and literature review. Case Rep Oncol Med. 2013;2013:354873.

9. Kutlay M, Cetinkal A, Kaya S, Demircan MN, Velioglu M, Berber U. Pediatric anaplastic parenchymal ependymoma: case report. Childs Nerv Syst. 2011;27(3):501505.

10. Lee SK, Lim DJ, Kim SD. Supratentorial cortical ependymoma in a 21-month-old boy. J Korean Neurosurg Soc. 2011;50(3):244-247.

11. Erdogan G, Ozel E, Pestereli HE, Salar Z, Tirak B, Karaveli S. Ovarian ependymoma. APMIS. 2005;113(4):301303.

12. Romero FR, Zanini MA, Ducati LG, Vital RB, de Lima Neto NM, Gabarra RC. Purely cortical anaplastic ependymoma. Case Rep Oncol Med. 2012;2012:541431.

13. Palma L, Celli P, Mariottini A, Zalaffi A, Schettini G. The importance of surgery in supratentorial ependymomas. Long-term survival in a series of 23 cases. Childs Nerv Syst. 2000;16(3):170-175.

14. Liu Z, Li J, Wang Q, Famer P, Mehta A, Chalif D, Wang Y, et al. Supratentorial cortical ependymoma: case series and review of the literature. Neuropathology. 2014;34(3):243252.

15. Niazi TN, Jensen EM, Jensen RL. WHO Grade II and III supratentorial hemispheric ependymomas in adults: case series and review of treatment options. J Neurooncol. 2009;91(3):323-328.

16. Ng DW, King NK, Foo AS, Sitoh YY, Lee HY, Ng WH. Anaplastic supratentorial cortical ependymoma presenting as a butterfly lesion. Surg Neurol Int. 2012;3:107.
17. Iwamoto N, Murai Y, Yamamoto Y, Adachi K, Teramoto A. Supratentorial extraventricular anaplastic ependymoma in an adult with repeated intratumoral hemorrhage. Brain Tumor Pathol. 2014;31(2):138-143.

18. Alexiou GA, Panagopoulos D, Moschovi M, Stefanaki K, Sfakianos G, Prodromou N. Supratentorial extraventricular anaplastic ependymoma in a 10-year-old girl. Pediatr Neurosurg. 2010;46(6):480-481.

19. Khilji MF, Hamid RS, Qureshi A. Supratentorial extraventricular anaplastic ependymoma in a child. BMJ Case Rep. 2014;2014.

20. Hamano E, Tsutsumi S, Nonaka Y, Abe Y, Yasumoto Y, Saeki H, Ito M. Huge supratentorial extraventricular anaplastic ependymoma presenting with massive calcification - case report. Neurol Med Chir (Tokyo). 2010;50(2):150153.

21. Van Gompel JJ, Koeller KK, Meyer FB, Marsh WR, Burger PC, Roncaroli F, Worrell GA, et al. Cortical ependymoma: an unusual epileptogenic lesion. J Neurosurg. 2011;114(4):1187-1194.

22. Moritani S, Kushima R, Bamba M, Kobayashi TK, Oka H, Fujimoto M, Hattori T, et al. Highly anaplastic extraventricular ependymoma arising in an adult, mimicking metastatic adenocarcinoma with heavy stromal inflammation and emperiporesis. Pathol Int. 2003;53(8):539-546.

23. Park EK, Lee YH, Kim DS, Choi JU, Kim TS, Shim KW. 17-year-old girl with headache and complex partial seizure. Brain Pathol. 2010;20(6):1111-1114.

24. Ohla V, Smith K, Drees C. Clinical status epilepticus due to anaplastic cortical ependymoma. Clin Neurol Neurosurg. 2012;114(6):710-712.

25. Vinchon M, Soto-Ares G, Riffaud L, Ruchoux MM, Dhellemmes P. Supratentorial ependymoma in children. Pediatr Neurosurg. 2001;34(2):77-87.

26. Takeshima H, Kawahara T, Uchida H, Hirano H, Nakazato Y, Kuratsu J. Brain surface ependymoma with repeated episodes of intratumoral hemorrhage - case report. Neurol Med Chir (Tokyo). 2002;42(4):166-169.

27. Kojima A, Yamaguchi N, Okui S, Kamiya M, Hirato J, Nakazato Y. Parenchymal anaplastic ependymoma with intratumoral hemorrhage: a case report. Brain Tumor Pathol. 2003;20(2):85-88.

28. Miyazawa T, Hirose T, Nakanishi K, Uozumi Y, Tsuzuki N, Shima K. Supratentorial ectopic cortical ependymoma occurring with intratumoral hemorrhage. Brain Tumor Pathol. 2007;24(1):35-40.

29. Singh V, Turel MK, Chacko G, Joseph V, Rajshekhar V. Supratentorial extra-axial anaplastic ependymoma mimicking a meningioma. Neurol India. 2012;60(1):111-113.

30. Roncaroli F, Consales A, Fioravanti A, Cenacchi G. Supratentorial cortical ependymoma: report of three cases. Neurosurgery. 2005;57(1):E192; discussion E192.

31. Garcia-Barriola V, De Gomez MN, Suarez JA, Lara C, Gonzalez JE, Garcia-Tamayo J. Ovarian ependymoma. A case report. Pathol Res Pract. 2000;196(8):595-599.

32. Furie DM, Provenzale JM. Supratentorial ependymomas and subependymomas: CT and MR appearance. J Comput Assist Tomogr. 1995;19(4):518-526.

33. Guerrieri C, Jarlsfelt I. Ependymoma of the ovary. A case 
report with immunohistochemical, ultrastructural, and DNA cytometric findings, as well as histogenetic considerations. Am J Surg Pathol. 1993;17(6):623-632.

34. de Medeiros FC, de Albuquerque LA, Pittella JE, de Souza RB, Gomes Neto AP, Christo PP. Open-ring enhancement in pseudotumoral multiple sclerosis: important radiological aspect. Case Rep Neurol Med. 2014;2014:951690.

35. Wiestler OD, Schiffer D, Coons SW, Prayson RA, Rosenblum MK. Ependymoma. In: Kleihues P, Cavenee WK (eds). Pathology and Genetics of Tumours of the Nervous System. World Health Organization Classification of Tumours Lyon, IARC Press. 2000; p. 71-80.

36. Chow MS, Mercier PA, Omahen DA, Wood SL, Johnson JA. Recurrent exophytic meningioma in pregnancy. Obstet Gynecol. 2013;121(2 Pt 2 Suppl 1):475-478.

37. Bello MJ, de Campos JM, Vaquero J, Kusak ME, Sarasa JL, Rey JA. High-resolution analysis of chromosome arm $1 \mathrm{p}$ alterations in meningioma. Cancer Genet Cytogenet. 2000;120(1):30-36.

38. Collins VP. Mechanisms of disease: genetic predictors of response to treatment in brain tumors. Nat Clin Pract Oncol. 2007;4(6):362-374.

39. Korshunov A, Neben K, Wrobel G, Tews B, Benner A, Hahn M, Golanov A, et al. Gene expression patterns in ependymomas correlate with tumor location, grade, and patient age. Am J Pathol. 2003;163(5):1721-1727.

40. Schweitzer JS, Batzdorf U. Ependymoma of the cauda equina region: diagnosis, treatment, and outcome in 15 patients. Neurosurgery. 1992;30(2):202-207.

41. Jaeger M, Rickels E, Schmidt A, Samii M, Blomer U. Lumbar ependymoma presenting with paraplegia following attempted spinal anaesthesia. $\mathrm{Br} \mathrm{J}$ Anaesth. 2002;88(3):438-440.

42. Chapman AB, Abraham WT, Zamudio S, Coffin C, Merouani A, Young D, Johnson A, et al. Temporal relationships between hormonal and hemodynamic changes in early human pregnancy. Kidney Int. 1998;54(6):20562063.

43. Isaacs H. Fetal brain tumors: a review of 154 cases. Am J Perinatol. 2009;26(6):453-466.

44. Kaminski K, Bazowski P, Grzonka D, Adamowicz R, Muszer M. [Rare case of a malignant brain neoplasm in an 18-years old pregnant woman]. Ginekol Pol. 2003;74(6):472-474.

45. Nakamizo S, Sasayama T, Kondoh T, Inoue S, Shiomi R, Tanaka H, Nishihara M, et al. Supratentorial pure cortical ependymoma. J Clin Neurosci. 2012;19(10):1453-1455.

46. Yadav YR, Chandrakar SK. Pure cortical supratentorial extraventricular ependymoma. Neurol India. 2009;57(2):213-215. 